\author{
ACTA MYCOLOGICA \\ Vol. 46 (1): 19-25 \\ 2011
}

\title{
Ecology and plectology of Phlebia tremelloidea (Polyporales, Agaricomycetes)
}

\author{
IVAN V. ZMITROVICH ${ }^{1}$ and OLEG N. EZHOV ${ }^{2}$ \\ ${ }^{1}$ V.L. Komarov Botanical Institute, 2 Popov Street, RU-197376 St. Petersburg, Russia \\ iv_zmitrovich@mail.ru \\ ${ }^{2}$ Institute of Ecological Problems of the North, 23 North Dvina quay \\ RU-163000 Arkhangelsk, Russia, elegezhik@gmail.com
}

Zmitrovich I.V., Ezhov O.N.: Ecology and plectology of Phlebia tremelloidea (Polyporales, Agaricomycetes). Acta Mycol. 46 (1): 19-25, 2011.

A rare boreonemoral species, Phlebia tremelloidea (Bres.) Parmasto was characterized morphologically and ecologically basing on Russian material. The specified description of the species was given. The variability of top lamprocystidia, basidia and basidiospores of the fungus was revealed. An abhymenial, medullar, and subhymenial strates of the basidiocarp were characterized. The relationships between developmental environments and morphology of the fungus were discussed.

Key words: basal layer, boreonemoral forests, ecology, gelatinized basidiocarps, lamprocystidia, medullar layer, phlebioid fungi, slowly-growing resupinates, thickened hymenium

\section{INTRODUCTION}

Phlebia tremelloidea (Bres.) Parmasto $[=$ Ph. lindtneri (Pilát) Parmasto] is rare boreonemoral species known from several localities on Eurasian continent. Rather variable morphology of this species is a reason of its controversial descriptions as well as rich synonymy, sound for rare taxon. A new finding of this fungus in old boreal forest of Arkhangelsk Region (European Russia) feats us re-examine all accessible material on the species. Therefore, the purpose of the present note is generalization of data on taxonomy, morphology and ecology of Ph. tremelloidea. 


\section{MATERIAL AND METHODS}

All accessible material on Ph. tremelloidea, Phlebia lindntneri, Peniophora tremelloidea Bres., and Phlebia merulioidea Parmasto were involved into present investigation. The collections consist of material collected by the authors in some regions of Russia as well as selected specimens from the Mycological Herbarium of the Komarov Botanical Institute (LE) (Saint Petersburg).

All specimens were studied and preserved with standard methods. The macroscopic description was based on examination of the fresh material and the analysis of the photos.

The dried material was studied using light microscopic techniques. Microscopical study of basidiocarps was carried out as described by Gilbertson and Ryvarden (1986). Freehand sections and squash mounts of basidiocarps were examined in 5\% $\mathrm{KOH}$ and $2 \%$ Cotton Blue. Spore conglomerations were searched in hymenophoral gelatinose matrix. Spore measurements contained 30 spores per specimen. The following abbreviations were used: L - spore length, W - spore width, Q - quotient of the spore length and spore width (L/W ratio). Specimens are preserved in the herbarium of Komarov Botanical Institute (St. Petersburg, LE) and Institute of Ecological Problems of the North (Arkhangelsk, AR).

\section{RESULTS}

\section{SPECIES DESCRIPTION}

Phlebia tremelloidea (Bres.) Parmasto, Eesti NSV Tead. Akad. Toim., Biol. seer 16: 393, 1967.

三 Peniophora tremelloidea Bres., Ann. Mycol. 18: 48, 1920.

$=$ P. lindtneri Pilát, Bull. trimest. Soc. mycol. France 53: 97, 1937.

三 Phlebia lindtneri (Pilát) Parmasto, Wahlenbergia 1: 74, 1975.

三Hohenbuehelia lindtneri (Pilát) Spirin in Zmitr., V. Malysheva, E. Malysheva \& Spirin, Folia Cryptogamica Petropolitana 1: 71, 2004.

= Phlebia merulioidea Parmasto, Notul. syst. Sect. cryptog. Inst. bot. Acad. Sci. URSS 15: 127, 1962.

Basidiocarps annual to persisting, resupinate, widely effused, originated as orbicular patches $1-4 \mathrm{~cm}$ in diam. and $0.3-3 \mathrm{~mm}$ thick, which merge into continuous crusts up to $20 \mathrm{~cm}$ long, subhyaline, honey-yellow or pale-creamish with gray to tan tints. The consistency is tough gelatinose when fresh, hard corneous when dry. The margin free laying, 0.2-0.8 mm wide, radially fibrillose to ciliate, in inrolled parts squalid due to weakly differentiated cilia, of the same consistency and color as basidiocarp. Hymenophore gyrose, 0.2-1 mm thick, of typical merulioid appearance, gelatinose to corneous of the same color as basidiocarp, but with shine pruina due to free-leaving hymenial lamprocystidia; alveoles 0.3-0.5(2) mm wide (Fig. 1). 

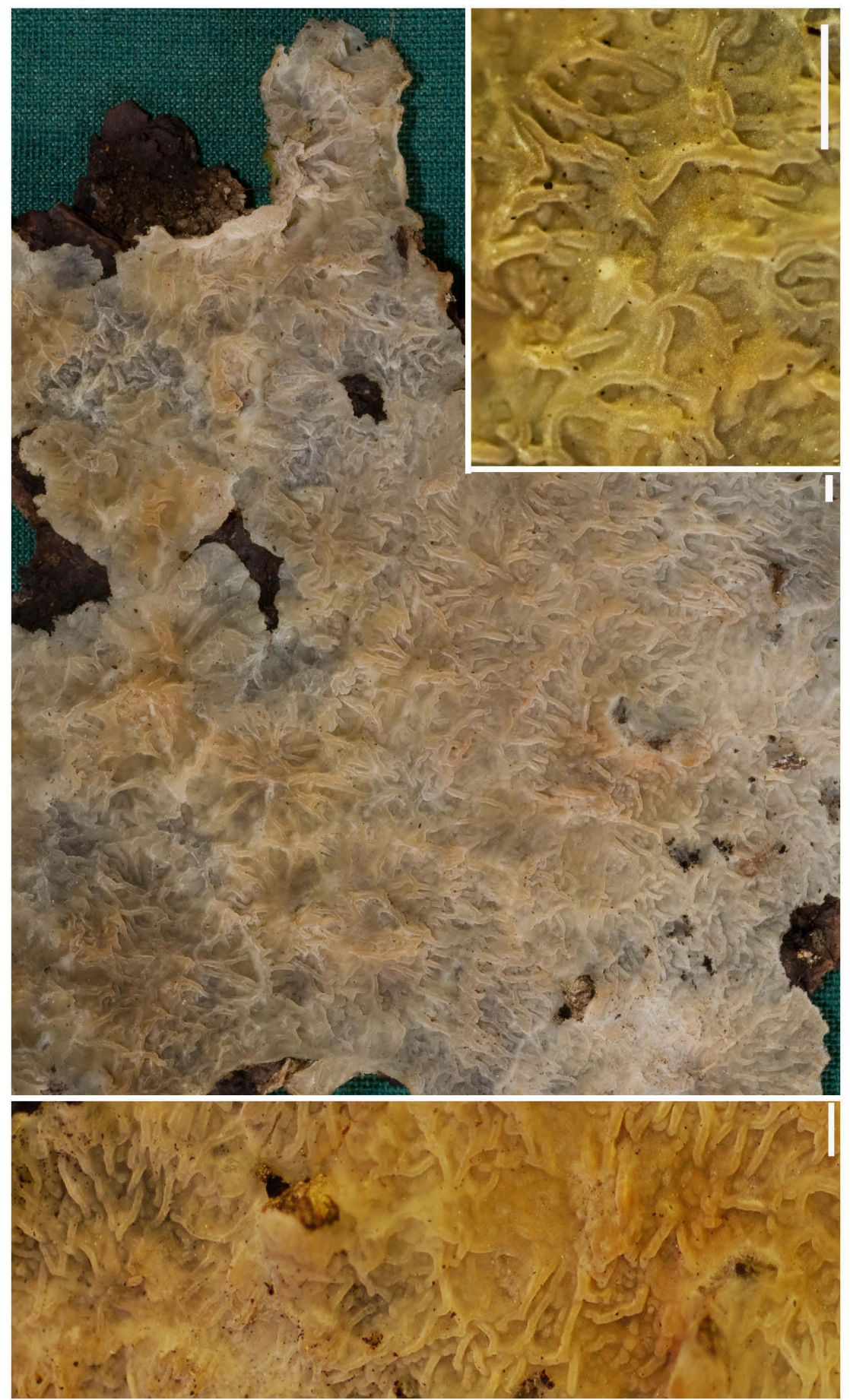

Fig. 1. Aspects of basidiocarp of Phlebia tremelloidea (fresh material; LE 269621) highlighting hymenophoral merulioid folds. Scale bar $=1 \mathrm{~mm}$ (photo R.V. Ershov). 

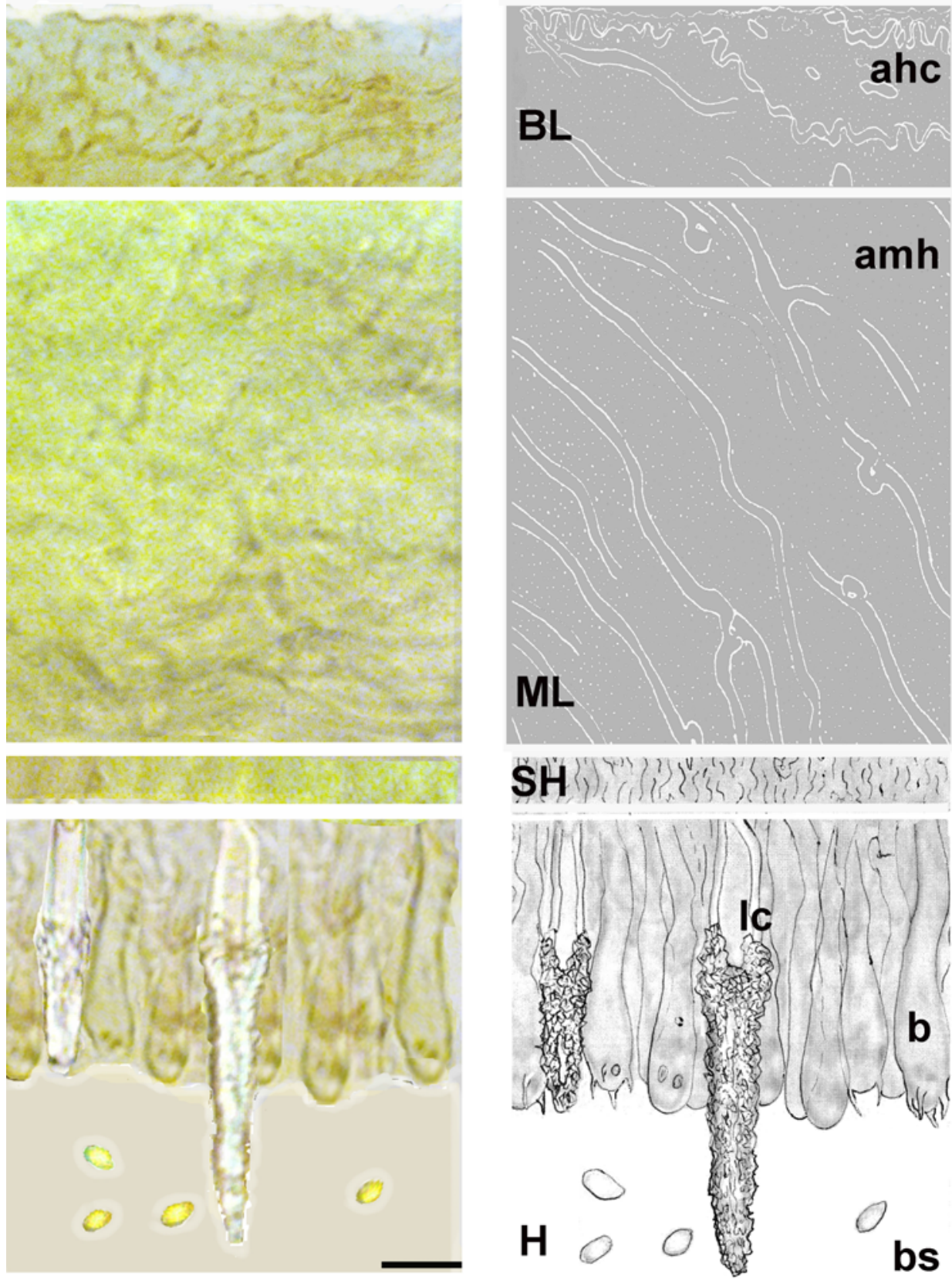

Fig. 2. Transverse section through basidiocarp of Phlebia tremelloidea: BL - basal layer with coiled agglutinated hyphae (ahc - agglutinated hyphae of cuticular cover); ML - agglutinated medullar hyphae ( $\mathrm{amh}$ ) producing a mucilaginous secret (gray phone) which forms cartilaginous matrix of basidiocarp; $\mathrm{SH}$ - subhymenium, composed by densely packed candelabriform hyphae; $\mathrm{H}$ - current hymenium with basidia (b), terminations of lamprocystidia (l) and basidiospores (bs). Scale bar $=10 \mu \mathrm{m}$ (fresh material; LE 269621). 
Hyphal system monomitic. Hyphae fibulate, hyaline, 1.5-3(7) $\mu \mathrm{m}$ in diam., with strongly gelatinized walls; in subhymenium 2-3 $\mu \mathrm{m}$ in diam, densely packed with formation of obscure textura porrecta; in medullar strate 2-5(7) $\mu \mathrm{m}$ free merged into gelatinose matrix, regularly branching, often inflated or coiled; near abhymenial surface $1.5-4 \mu \mathrm{m}$ in diam., coiled and densely packed into superficial fascicles, strongly agglutinated. Lamprocystidia originating from low medullar to hymenial and abhymenial layers, abundant (predominating in fold areas), 60-120 × (5)9-12(18) $\mu \mathrm{m}$ (encrusted part varying between 38-60 × 8-18 $\mu \mathrm{m}$; Tab. 1), subulate to fusoid, initially naked and with slightly thickened walls, in maturity thick-walled and heavily encrusted in the top third (ecncustation pyramidal crystalline, oxalate). Basidia long-cylindrical, 31-42 × 3.9-5.1 $\mu \mathrm{m}$, 4-spored, with weak constriction and a clamp at the base (Tab. 1). Basidiospores 4.8-7.2 $\times$ 2.5-4.1 $\mu \mathrm{m}$, ellipsoid to ovoid, slightly flattened, thin-walled, inamyloid, hyaline, with numerous small droplets (Tab. 1, Fig. 2).

Table 1

Variability of diagnostically important microstructures in Phlebia tremelloidea (fresh material LE 269621)

\begin{tabular}{|c|c|c|c|c|c|c|c|c|}
\hline \multicolumn{3}{|c}{$\begin{array}{c}\text { Encrusted parts of } \\
\text { lamprocystidia }\end{array}$} & \multicolumn{3}{c|}{ Basidia } & \multicolumn{3}{c|}{ Basidiospores } \\
\hline $\mathrm{L}$ & $\mathrm{W}$ & $\mathrm{Q}$ & $\mathrm{L}$ & $\mathrm{W}$ & $\mathrm{Q}$ & $\mathrm{L}$ & $\mathrm{W}$ & $\mathrm{Q}$ \\
\hline 42 & 11 & 3.8 & 32 & $\mathbf{3 . 9}$ & 8.2 & 5.2 & 2.9 & 1.8 \\
\hline 48 & 11 & 4.4 & 39 & 4.1 & 9.5 & 5.4 & 3 & 1.8 \\
\hline 38 & 10 & 3.8 & 35 & 4.5 & 7.8 & 5.5 & 3.9 & 1.4 \\
\hline 52 & 15 & 3.5 & $\mathbf{3 1}$ & 4 & 7.8 & 4.9 & 3.2 & 1.5 \\
\hline 58 & 13 & 4.5 & $\mathbf{4 2}$ & 5 & 8.4 & $\mathbf{7 . 2}$ & 3.9 & 1.8 \\
\hline 45 & 12 & 3.8 & 31 & 4.5 & $\mathbf{6 . 9}$ & 5 & 2.9 & 1.7 \\
\hline 50 & $\mathbf{1 8}$ & $\mathbf{2 . 8}$ & 35 & 4.6 & 7.6 & 5.3 & 3 & 1.8 \\
\hline 58 & 15 & 3.9 & 32 & 3.9 & 8.2 & 5.1 & 2.6 & 2.0 \\
\hline $\mathbf{6 0}$ & 18 & 3.3 & 35 & 4.9 & 7.1 & 5.4 & 2.8 & 1.9 \\
\hline 48 & 12 & 4.0 & 32 & 4 & 8.0 & 7.8 & $\mathbf{4 . 1}$ & 1.9 \\
\hline 45 & 10 & 4.5 & 41 & 4.5 & 9.1 & $\mathbf{4 . 8}$ & $\mathbf{2 . 5}$ & 1.9 \\
\hline 56 & 12 & $\mathbf{4 . 7}$ & 42 & $\mathbf{5 . 1}$ & 8.2 & 5.2 & 3 & 1.7 \\
\hline 62 & 17 & 3.6 & 35 & 5 & 7.0 & 5.7 & 2.8 & 2.0 \\
\hline 45 & 15 & 3.0 & 32 & 4 & 8.0 & 5.1 & 2.8 & 1.8 \\
\hline $\mathbf{3 8}$ & 10 & 3.8 & 30 & 3.9 & 7.7 & 5.2 & 2.7 & 1.9 \\
\hline 47 & 13 & 3.6 & 32 & 4.6 & 7.0 & 6.5 & 3.5 & 1.9 \\
\hline 42 & 14 & 3.0 & 33 & 3.9 & 8.5 & 5.9 & 2.9 & 2.0 \\
\hline 38 & 9 & 4.2 & 38 & 4 & 9.5 & 5.2 & 3 & 1.7 \\
\hline 35 & $\mathbf{8}$ & 4.4 & 42 & 5 & 8.4 & 5.2 & 2.5 & 2.1 \\
\hline 45 & 10 & 4.5 & 38 & 4.2 & 9.0 & 4.8 & 2.5 & 1.9 \\
\hline 48 & 12 & 4.0 & 42 & 4.7 & 8.9 & 6.2 & 3.2 & 1.9 \\
\hline 39 & 10 & 3.9 & 40 & 5 & 8.0 & 5.1 & 3.1 & 1.6 \\
\hline 45 & 15 & 3.0 & 33 & 4.5 & 7.3 & 6.5 & 3.1 & 2.1 \\
\hline 58 & 16 & 3.6 & 33 & 3.9 & 8.5 & 7 & 4.1 & 1.7 \\
\hline 39 & 10 & 3.9 & 35 & 4 & 8.8 & 5.3 & 3.2 & 1.7 \\
\hline 55 & 15 & 3.7 & 38 & 4.1 & 9.3 & 5.2 & 2.8 & 1.9 \\
\hline 45 & 13 & 3.5 & 42 & 5 & 8.4 & 6 & 3.5 & 1.7 \\
\hline 38 & 10 & 3.8 & 39 & 3.9 & $\mathbf{1 0 . 0}$ & 5.5 & 3.2 & 1.7 \\
\hline 55 & 14 & 3.9 & 40 & 4.5 & 8.9 & 5.8 & 3.2 & 1.8 \\
\hline 42 & 12 & 3.5 & 38 & 4.2 & 9.0 & 5.2 & 2.8 & 1.9 \\
\hline 47.2 & 12.7 & 3.8 & 36.2 & 4.4 & 8.3 & 5.6 & 3.1 & 1.8 \\
\hline
\end{tabular}

Abbreviation. The limiting dimensions marked by boldface. 
On bark or fully decorticated areas of fallen logs on Abies sibirica, Picea abies, Alnus incana, Populus tremula, and Quercus robur in old boreal or boreonemoral forests. Associated with a white rot.

SPECIMENS EXAMINED. Russia: Arkhangelsk Region: Koryazhma vicinities, Oxalis acetosella spruce-fir forest, on bark of fallen Abies sibirica, 9.VIII.2010, leg. O.N. Ezhov (LE 269621). Leningrad Region: Vsevolozhsk District, Vaskelovo vicinities, Aegopodium podagraria alder forest, on bark of fallen Alnus incana, 27.VIII.1997, leg. I.V. Zmitrovich (LE 214796; as Phlebia lindtneri). Nizhegorod Region: Kerzhensky Reserve, floodland of Kerzhenetz, on decorticated fallen log of Quercus robur, 10.X.1999, leg. W.A. Spirin (LE 208542; as Phlebia lindtneri). Krasnoyarsk Region: Enisey District, Kolchym vicinities, fir forest, on fallen decorticated Populus tremula, 14.VIII.1959, leg E. Parmasto (LE 22527; isotype of Phlebia merulioidea).

\section{DISCUSSION}

Taxonomical history. The type species was described by Bresadola (1920) in genus Peniophora Cooke due to its striking encrusted lamprocystidia and hard hymenium with thickened subhymenieum. Some years later, Pilát described his Peniophora lindtneri (Pilát 1937) sufficiently corresponded to Bresadolian P. tremelloidea. Parmasto (1967) shifted P. lindtneri into genus Phlebia Fr. on the reason of its gelatinized textura and more appropriate to Phlebia characteristics of cystidia, basidia, and basidiospores. In such a status, the name was in wide use (Eriksson et al. 1981; Jülich, Stalpers 1980; Kotiranta, Saarenoksa 2000). Parallelly, Parmasto described Phlebia merulioidea (Parmasto 1962) for the fungus sufficiently corresponded to Ph. tremelloidea and Ph. lindtneri. As a difference of newly described species from 'Peniophora tremelloides', this author mentioned its narrower thin-walled hyphae (1.4-4.5 vs 4-7 $\mu \mathrm{m})$ and smaller basidiospores $(4.5-5.5 \times 2.3-2.8$ vs 6-7 $\times 4-5 \mu \mathrm{m})$. The further investigations of microstructures of both species fall the border between these (see Tab. 1).

The position of the species within genus Phlebia is rather stable and widely accepted. Only in 2004, it was made new combination Hohenbuehelia lindtneri (Pilát) Spirin (Zmitrovich et al. 2004) on the base of metuloid-like lamprocystidia and a local attachment area of basidiocarp, corresponded with consideration on merulioid fungi as resupinate agarics with disturbed morphogenesis. However, strict phlebioid textura of basidiocarp has forced a re-evaluation of this position for the benefit of recognizing a separate unit of generic rank, Lampromerulius Zmitr. \& Spirin ined. (Spirin, Zmitrovich 2009).

The recent molecular study of phlebioid fungi (Moreno et al. 2010) based on divergence revealing by ITS and partial 28S rDNA sequences not supported an isolated position of 'Lampromerulius': the sequence Ph. lindtneri was clustered with those of 'Steccherinum' lusitanicum (Bres.) Ryvarden and Phlebia setulosa (Berk. \& M.A. Curtis) Nakasone in core-Phlebia clade. Therefore, the lamprocystidia presence and construction is trailer apomorphy needed in ecomorphological rather than phylogenetical interpretation.

Plectology. The hyphae of $P h$. tremelloidea produce mucilaginous substance that leads to cartilaginous context of basidiocarp. Such a feature is connected to 
reduction of water loss by evaporation and protection the protein bearing hyphae of the deeper regions against microscopic animals, such as mites and spring tails. Gelatinized contexts represent a certain water reserve and give important volume to a basidiocarp without engaging much biomass (Clémençon 2004).

The basal layer of basidiocarp of $P h$. tremelloidea represents an agglutinated hyphal mass forming dense abhymenial plate, i.e. this layer cannot be interpreted as subiculum, rooted into substrate (Fig. 2). The hyphae in this layer are variable in diameter (1.5-4 $\mu \mathrm{m}$ wide) and often bear thickened walls that more precisely can be interpreted as prominent glucane cover. Usually, under $5 \% \mathrm{KOH}$ these thick-walled hyphae dissolve and stay subinvisible. The hyphal arrangement in this layer is more or less horizontal. Near the margin the hyphae form ciliar agglutinated fascicles, furnished by occasional lamprocystidia.

The medullar layer of basidiocarp in Ph. tremelloidea is weakly differentiated from upper and lower strates. This is a huge cartilaginous mass composed by freeleaving strongly gelatinized hyphae. As it seen on figure 2, the hyphal mass of this layer is subinvisible due to mucilaginous substance. The hyphae in this layer have descending orientation. Near to subsequent subhymenial strate, some hyphae bear fusiform apical thick-walled swellings. These are precursors of lamprocystidia. In general, hyphal masses of medullar layer form a certain fascicular zones corresponded to hymenophoral ridges. The hyphal ends in these ridges have a tendency to lamprocystidia formations.

The fungus in question is characterized by thickened hymenium (auxohymenium according to Clémençon 2004), i.e. candelabriform structure leading to textura porrecta, which is a result of replacement of old basidia by new ones springing from ramifications of the same candelabra growing beyond the general level of the hymenium. In Ph. tremelloidea this layer is enriched and strengthened by mature lamprocystidia. The roots of these strucures are hidden among subhymenial textura porrecta, but in some cases we can mark a total length which reaches $120 \mu \mathrm{m}$. However, encrusted part, which consists as a rule $1 / 3$ of total length, is easily observable, and varies in limits 38-60 × 8-18 $\mu \mathrm{m}$ (Tab. 1).

The current hymenium of $P h$. tremelloidea composed by basidia, lamprocystidial ends and small young lamprocystidia (Fig. 2). Basidia of characteristic for Phlebia type - an elongated, cylindrical with weak constriction and clamp at the base, the limits of their variability 31-42 × 3.9-5.1 $\mu \mathrm{m}$ (Tab. 1). Agglutinated area of hymenial surface bear a lot of ellipsoid and slightly flattened thin-walled basidiospores 4.8-7.2 $\times$ 2.5-4.1 um (Tab. 1, Fig. 2).

Ecology. Ph. tremelloidea is sparsely distributed in forest zone of Western and North Europe (Bresadola 1920; Pilát 1937; Ryvarden et al. 1981; Hansen, Knudsen 1997; Kotiranta, Saarenoksa 2000) and European (Spirin 2002; Zmitrovich et al. 2004) and Asian (Parmasto 1962, 1968) Russia.

As preferred communities were mentioned fir forest (Parmasto 1962), pine and spruce-mixed forests (Ryvarden et al. 1981), juniper-mixed herb-rich spruce forest (Kotiranta, Saarenoksa 2000), nemoral floodland (Spirin 2002), and herb-rich alder forest (Zmitrovich et al. 2004).

Our new finding in Arkhangelsk Region was made in mixed spruce-fir forest (Picea abies, Abies sibirica) of diverse age with some intrusions of pine (Pinus sylvestris), birch (Betula pubescens) and aspen (Populus tremula). An average age of 
stand consists 160-180 years, the spruce actively falls, therefore there are some clear areas enriched by gross wood-debris. The soil cover is presented by Oxalis acetosella, Vaccinium myrtillus, Hylocomium splendens, Dryopteris filix-mas. This type can be characterized as Piceeto-Abiegnetum meso-hygrophilico herbosum. The fungus was attached to shady site of community. Other members of local fungal community are Oligoporus immitis (Pers.) Niemelä (aspen), Amylocystis lapponicus (Romell) Bondartsev \& Singer, Phellinus chrysoloma (Fr.) Donk, Phlebiopsis gigantea (Fr.) Jülich, Pycnoporellus fulgens (Fr.) Donk (spruce), Phellinus pini (Brot.) Bondartsev \& Singer, Skeletocutis carneogrisea A. David (pine), Oligoporus rancidus (Bres.) Gilb. \& Ryvarden (fir).

Concerning substrata, the fungus was reported from Populus tremula (Parmasto 1962), Picea abies and Pinus sylvestris (Ryvarden et al. 1981), Juniperus communis (Kotiranta, Saarenoksa 2000), Quercus robur (Spirin 2002) and Alnus incana (Zmitrovich et al. 2004). Our finding in Arkhangelsk Region is associated with fallen Abies sibirica, diameter of $\log$ reaches $28 \mathrm{~cm}$. It is necessary to mention that material on Populus tremula, Quercus robur, and Alnus incana is associated with strictly decorticated areas, whereas our material on Abies sibirica is associated with uncracked bark.

The fungal outgrowths appear from underside of fallen logs as roundish patches having an intermerging tendency. The margin generally adhere the substrate, but without rooting into them. Some specimens demonstrate inrolled margin with naked or pruinose (on the manner of Phlebia centrifuga P. Karst.) abhymenial surface. The fact that fully developed basidiocarps can be revealed in August (Parmasto 1962; Zmitrovich et al. 2004; the present data) and keep up to October (Kotiranta, Saarenoksa 2000; Spirin 2002) (and, possibly, later) forces us suppose that the fungus is a slowly growing with potential to survive of winter season. The clearly thickened subhymenium protruded by lamprocystidia supports Parmasto (1962) interpretation of hymenium of the fungus as 'multilayered'. The observations of the fungus during some years are needed to revealing of persisting capacity of this species.

\section{CONCLUSION}

Ph. tremelloidea is a slowly-growing phlebioid fungus adapted to colonization of homogeneous (not cavernose) substrata, like decorticated wood or uncracked bark. In contrast to relatives having a transcortical development, like $P h$. radiata Fr. or $P h$. rufa (Pers.) M.P. Christ., this fungus haven't reserved superficial vegetative mass. Therefore, its growth is more slow and even. The numerous lamprocystidia create a rigid skeleton which promotes to constant increasing of hymenial field. The fungus attached to soft conditions of old forests with abundance of fallen logs that allows a long-term (to persisting) sporulation.

Acknowledgements. The authors are very grateful to Dr. R.V. Ershov for discussions on this interesting species and the photos. Financial support from RFBR grants "Regularities of mycobiota formation of boreal forests on North-West of Russia in cretaceous landscapes environments" (N 08-04-98805-p_north_a) and "Substrate preference and spatial structure of biota of aphyllophoroid fungi in nature ecosystems of European Russia” (09-04-01064-a). 


\section{REFERENCES}

Bresadola G. 1920. Selecta mycologica I. Ann. Mycol. 12: 26-70.

Clémençon H. 2004. Cytology and plectology of the Hymenomycetes. Bibl. Mycol. 199: 1-488.

Eriksson J., Hjortstam K., Ryvarden L. 1981. The Corticiaceae of North Europe. 6. Phlebia - Sarcodontia. Fungiflora, Oslo: 1051-1276.

Gilbertson R. L., Ryvarden L. 1986. North American polypores. 1. Fungiflora, Oslo, 436 pp.

Hansen L., Knudsen H. (eds). 1997. Nordic macromycetes. 3. heterobasidioid, aphyllophoroid and gastromycetoid Basidiomycetes. Nordsvamp, Copenhagen, $445 \mathrm{pp}$.

Jülich W., Stalpers J.A. 1980. The resupinate non-poroid Aphyllophorales of the Northern Hemisphere. North-Holland Pub. Comp., Amst.; Oxf.; New York, 335 pp.

Kotiranta H., Saarenoksa R. 2000. Corticioid fungi (Aphyllophorales, Basidiomycetes) in Finland. Acta Bot. Fennica 168: 1-55.

Moreno G., Blanco M.-N., Platas G., Peláez F. 2010. Taxonomic and phylogenetic revision of three rare irpicoid species within the Meruliaceae. Mycol. Progress 10 (a preprint).

Parmasto E. 1962. Species varietatesque novae fungorum. Tremellales et Aphyllophorales. Notulae systematicae e Sectione Cryptogamica Instituti Botanici nomine V.L. Komarovii Academiae Scientiarum URSS 15: 125-137.

Parmasto E. 1967. Corticiaceae U.R.S.S. IV. Descriptiones taxorum novarum. Combinationes novae. Eesti NSV Tead. Akad. Toimet. Biol. 16: 377-394.

Parmasto E. 1968. Conspectus systematis Corticiacearum. Inst. Zool. Bot., Tartu, 261 pp.

Pilát A. 1937. Addimenta ad floram Sibiriae Asiaeque orientalis mycologicam. Pars IV. Bull. Soc. mycol. France 52: 305-336.

Spirin W.A. 2003. Aphyllophoraceous fungi of Nizhegorod Region: Species composition and ecological peculiarities. PhD Thesis. Komarov Botanical Institute, St. Petersburg, 242 pp.

Spirin W.A., Zmitrovich I.V. 2009. Phaeophora: New taxa compendium. Komarov Botanical Institute, St. Petersburg. $1 \mathrm{~S}$. (in Latin, a manuscript).

Zmitrovich I.V., Malysheva V.F., Malysheva E.F., Spirin W.A. 2004. Pleurotoid fungi of Leningrad Region (with notes on rare and interesting East European taxa). Folia crypt. Petropolitana 1: 1-124. 